\title{
И.В. Кирдяшкин
}

\section{ПОЛИТИЧЕСКАЯ СОЦИАЛИЗАЦИЯ КАК «ЗАБОТА О СЕБЕ» В КОНТЕКСТЕ КУЛЬТУРНО-СИМВОЛИЧЕСКИХ СЦЕНАРИЕВ КОММУНИКАЦИИ}

\begin{abstract}
Политическая сочиализачия представлена в качестве составляющей социильной «заботы о себе», которая содержит перформативный характер и происходит в контексте культурно-символических сиенариев коммуникации. Они обеспечивают смысловую автономию, восприимчивость социальной «заботы о себе» $\kappa$ эволючии культуры социума. При этом данные сценарии выступают проявлениями самосознания общества, средствами выбора форм и значений социального общения, понимания политических явлений.

Ключевые слова: политическая социализация, «забота о себе», культурно-символическое конструирование политического, сочиальное самосознание.
\end{abstract}

Неустойчивость структур современного общества, неопределенность векторов его изменений требуют от личностей способностей к участию в воссоздании и деконструкции социума, общественного целеполагания. Особое значение при этом имеет политическая социализация. Политическое как предмет познания личности в политической социализации предстает способом воспроизводства и поиска новых границ смыслов и форм человеческой активности в социуме, раскрытия и сохранения истоков его потенциальности. В частности, в творчестве Э. Гуссерля роль политического определяется в контексте проблемы взаимоотношений жизненных миров и ситуации притязаний, всемирно-исторической борьбы за жизненный мир человека как первичную данность, «всеобщую почву» человеческой жизни в мире, горизонт интерсубъективных значений, ценностей индивида [1. С. 380-381]. Политическое в работах Э. Гуссерля происходит под воздействием предельно «непонятного», «ненормального» опыта «чужого», идущего вразрез с жизненным миром, устанавливающим свою «естественную» границу в качестве генеративно общего [Там же. С. 383-384]. В этом плане политическая социализация формирует возможности для осознания особенностей и трансформаций жизненного мира личностей, придания социуму ценностно-нормативной автономности, раскрытия творческого потенциала данной отличности в мире живого. При этом становление человека политического сопряжено с включением личности в политическую культуру. Она, выражая эволюцию ведущих свойств жизненного мира личностей, содержит в себе потенциал для управления процессами кооперации, конвергенции разных векторов человеческой активности, ее жизненных миров, образуя их разнообразную общность и целенаправленность в окружающем мире, в эволюции живого.

В этом плане базовым аспектом включения человека в политическую культуру является его вовлечение в сферу и динамику форм общественной солидарности, процессы осознания содержательной направленности, ценности межчеловеческих отношений. Они, в свою очередь, как отмечает Ю.М. Резник, 
могут быть основаны, в частности, на идеях духовного братства Н.А. Бердяева, мирности (или «мирскости») человеческого бытия М. Хайдеггера. Мирскость, по М. Хайдеггеру, есть стремление человека быть везде, как у себя дома. Она дополняется заботой о своем бытии и созданием мира для человека, где он перестает быть только «хозяином» или «демиургом». При этом речь идет о культивировании особой экологии человеческого существования и признания ценности и разнообразия всего сущего на планете, его взаимосвязанности и целокупности [2. С. 27], о стремлении индивидов не к достижению консенсуса или общественного договора любой ценой, а к сообществам, соответствующим образу мышления и стилю жизни человека, способным поддерживать баланс с окружающим миром [Там же. С. 28]. В данном контексте условием политического, в частности, государства становится культурный феномен заботы человека и общества о обеспечении взаимосвязей индивидов, их сообществ, уровней и форм живого на планете.

Проявления заботы о совместном бытии с другими индивидами и уровнями живого включают в себя «практики себя». Они нацелены на самопреобразование, обеспечение готовности человека к социальному бытию, участию в воспроизводстве и обновлении коммуникации с другими индивидами, уровнями и способами бытия человека в разных, меняющихся контекстах. Это позволяет формировать политическую культуру человека, включающую в себя набор средств понимания общества как взаимосвязанной процессирующей культурно-исторической целостности, сообщающейся на основе возникновения и трансформаций общности мировидения индивидов. Фундаментальное значение политического, как отмечает П. Рикер, состоит в объединении интересов, устремлений человеческого существования, базирующихся на переломе в сфере мышления [3. С. 292]. В этом отношении М. Фуко видел исток человека политического в практиках преодоления «пределов себя» и реализации событий переходов личности в новые состояния как в «заботу о себе» [4. С. 50]. В практиках «заботы о себе», по М. Фуко, происходит обретение опоры в отношении к миру, к другим, понимание взаимосвязей с ними. В них человек обнаруживает себя членом человеческого сообщества, обретает качества, необходимые для подключения к разным формам социальной активности [Там же. С. 586-587].

При этом «забота о себе» в античной философии, в частности у Платона, отмечает М. Фуко, это «момент пробуждения» [Там же. С. 20] и условие обретения возможности управления другими [Там же. С. 91]. Идея и практики «заботы о себе» представляют, как считает М. Фуко, вид изменения отношений к себе, к другим, к миру, отчетность за своим мышлением и соответствующие действия, преображающие личность [Там же. С. 23]. М. Фуко выделяет два вида преображения, через идеи эпистрофэ и матанойи. В философии Платона практики преображения человека предстают как возвращение к себе, к лону, к началу, как припоминание себя, воспоминание корней, т.е. идею эпистрофэ [Там же. С. 235]. Идея метанойи - это идея покаяния и внезапной перемены образа мыслей, коренной ломки образа мыслей, преодоления опыта и возрождения человека заново, происходящего внутри истории. Эта идея, произрастая в античности, получает наибольшую силу вместе с христианской культурой [Там же. С. 237]. Метанойя обозначает переход от одного бытия к другому, рождение нового человека и одновременно его отказ от самого себя, 
себя прошлого, разрыв с собой [4. С. 238]. При этом одновременно «забота о себе» предстает и как «возращение к себе», которое всегда одиссея, для которой необходимо соответствующее знание [Там же. С. 275], возникающее в практиках самопознания и самопреобразования как практиках «управления собой» и истоках возможностей управления другими [Там же. С. 278]. Это продуцирует культурный актив, позволяющий личности и социуму осуществлять самотрансцендирование и «управление собой», являющиеся условием жизнетворчества. «Забота о себе» предстает присущей значениям политического, сопряженностью с инициированием выхода личности и человеческого социума в целом на новые уровни самоорганизации под влиянием чужого, непонятного, воздействия качественно отличных свойств жизненных миров.

Современность привносит в «заботу о себе» как выражение значений политической компоненты социума идею виртуозности. Она предполагает наличие принципиальной неполноты знаний об обществе. П. Вирно рассматривает виртуозность как особый вид коммуникации, обусловленный личностной импровизацией и мастерством, творчеством мировидения и социальных отношений. Значение виртуозности философ выводит из «Никомаховой этики» Аристотеля. В ней, пользуясь понятием виртуозности, Аристотель разделяет работу, или пойезис, и политическое действие, или праксис. Аристотель, отмечает П. Вирно, считал, что цель творчества (poiesis) отлична от него самого, а цели поступка (praxis), понимаемого как этическое поведение и как политическое действие, видимо, нет, ибо здесь целью является само благо-получение в поступке [5. С. 53]. Идея виртуозности сопряжена с понятием «оперативного времени» или временем kairos у Дж. Агамбена. Оно выступает как специфическим образом сокращенный текущий chronos или мессианское время, coвершающее политические события, образующие «окна» в текущем времени для проникновения непривычного, спрятанного и проявляющегося в человеческом экзистенциальном. Благодаря kairos, отмечает философ, схватывается представление о человеке во времени. Это время, пишет Дж. Агамбен, является временем, которым «мы сами являемся» [6. С. 92-93]. Kairos как прорыв иного, непонятного является условием складывания и модификации политического, становящегося в качестве способа работы общества с непредвиденным, сложным, непредсказуемым.

В понятии «виртуозность» П. Вирно видит потенциал политического, которое философ трактует как способ отношения с непредвиденностью. Политика, по П. Вирно, проявляет себя как общечеловеческий опыт извещения о чем-либо новом, внутренние отношения со случаем и непредсказуемостью [5. С. 50]. Вместе с тем виртуозность обозначает наметившийся «разрыв» между человеком с его собственным социальным измерением, что инициирует размыкание его смысловых структур. Как считает П. Вирно, любую политическую деятельность сближает с виртуозностью отсутствие «законченного продукта». И наоборот, любая виртуозность внутренне политична [4. С. 54]. Идея виртуозности делает «заботу о себе» процессом, направленным на раскрытие новых граней и расширение жизненного мира личности как границ его самопреобразования, творческих проявлений и самоконтроля, понимания политических феноменов.

Символическим пространством проявления виртуозности в политической социализации личности выступает, в частности, современная система 
образования. В ней, считает М.Н. Эпштейн, потенциально возможно непосредственное и спонтанное в диалоге с другими индивидами таинство творческой самореализации, «преображение-через-знание». Образование - импровизационная деятельность, включающая коллективную импровизацию, развивающая способность удивляться, поступать непредсказуемо [7. С. 38].

В плане «заботе о себе» присуща культурная перформативность. Она, замечают исследователи, помещает человека на границу между художественным и реальным миром [8. С. 321]. Перформанс как культурное явление, считает Е.В. Шмелева, объединяет возможность балансирования на границе фиктивного и реального, преодоления границ публичного / приватного, визуального восприятия / тактильного, дистанцию / близость [9. С. 124]. Э. Фишер-Лихте видит в эстетике перформативности отказ от мышления, основывающегося на принципе дихотомии, допущение многозначности, побуждающей человека вести себя так, как это происходит, например, в спектакле [8. С. 375]. Под перформансом исследователи также понимают социальный процесс, посредством которого индивиды и сообщества доносят смысл собственной социальной ситуации [10. С. 79].

Культурный перформанс сопровождается перформативными высказываниями, которые, согласно Дж. Остину, по сравнению с конститутивными, описывающими реальность, построены по модели «я клянусь», «я обещаю», «сим объявляю», создавая факты [11. С. 263]. Перформативные высказывания создают и преобразуют реальность, меняют ее, учреждают порядки, создают социально значимые эффекты. В перформативных высказываниях, считают исследователи, можно увидеть первичное ядро коммуникации [10. С. 78]. По мнению Дж. Батлер, проявления перформативности свидетельствуют об уязвимости как свойстве жизни индивидов, ее нехватке, требующей «заботы о себе». Перформативность превращает эту слабость в силу. Согласно Дж. Батлер, именно необходимость справляться с материальной нуждой, социальной несправедливостью, тревогой соединяет хрупкие жизни в их уязвимости и придает им политический смысл [12. С. 218]. «Забота о себе» предстает как множество перформативных актов, порождающих ее множественные векторы и формы жизни индивида. Они выражают разные аспекты понимания социальной ситуации человека. Перформативность наделяет «заботу о себе» возможностью социокультурного конструирования политических явлений, политической культуры в процессе политической социализации личности.

Вместе с тем, по мнению Дж. Агамбена, эффект перформатива обладает своей силой благодаря связи с древнейшими магическими слоями языка, дающими возможность верить в сказанное. Философ, исследуя перформативы, выделяет их сакральные корни, конституирующие, в том числе, политическую теологию, базирующуюся на древнейших магических пластах языка [6. С. 170]. Перформатив, считает Дж. Агамбен, свидетельствует о том этапе человеческой культуры, когда язык соотносился не с вещами на привычной нам основе констативных или истинностных отношений, а посредством особой операции, в которой речь заклинает вещи и сама является фундаментальным фактом [Там же. С. 171]. По мнению философа, теологические истоки современных политических концептов продолжают действовать внутри них, ориентируя сам образ политического мышления [13. С. 501]. Дж. Агамбен выделяет обусловленность современной власти теологическими категориями как ее истинными 
скрытыми претензиями и истоками, приближаясь к сути скрытых сценариев, определивших и продолжающих определять природу власти [13. С. 505]. В этом отношении перформативность в конкретном высказывании создает эффект коллективного присутствия и этической консолидации сообщества, включенной в пространство сценического, присущего ритуалу, конвенционального действия, поддерживающего социальную реальность [6. С. 78].

В этом плане «забота о себе» как перформативная социокультурная практика происходит в контексте процессов эволюции значимых для многих индивидов несущих культурных конструкций общественной коммуникации, продуцирующих ее события и удерживающих их последовательность, релевантность друг другу. В коммуникации, согласно Н. Луману, происходит конструирование действия, понимание, порождающее его бифуркации [14. C. 144]. При этом коммуникация строится на основе каких-либо ожиданий как структур, благодаря которым одна операция коммуникации может подсоединять к себе другие [Там же. С. 106]. Среди данных ожиданий Н. Луман выделяет когнитивные ожидания, нацеленные на обновление способов соединения коммуникаций в динамике [15. С. 69]. К культурным формам проявления и образования данных ожиданий относятся, в частности, культурносимволические сценарии коммуникации. Сценарий в самом общем плане, считает А.Ф. Алиференко, сопряжен с динамикой и хронотопом, позволяет упорядочивать стандартную последовательность событий [16. С. 191]. В этом плане сценарий коммуникации позволяет организовывать «практики себя» в контексте многих парадигм, действий и форм, ценностей и смыслов социального становления человека. Сценарии коммуникации позволяют преодолевать границы дифференциаций, форм и смыслов трансформаций общества и личности посредством символов. Символы, как отмечает Э. Кассирер, конструируют реальность [17. С. 16]. В качестве способа понимания общей направленности культурные сценарии коммуникации символически собирают практики и элементы «заботы о себе» во взаимосвязанный многообразный и целенаправленный процесс самопреобразования общества и личности.

В этом плане в исследованиях С.В. Лурье культурный сценарий выступает комплексом восприятия, определяющим значимость тех или иных компонентов культуры в социализации, выражающих установки на принципиально возможные в культуре действия [18. С. 160-161]. Символический сценарий коммуникации предстает возможным в культуре общества способом реализации и трансформации практик самопознания и самоконтроля. О возможном высказывались, в том числе, античные философы, в частности, Аристотель [19. С. 307]. Он считал, что действительность предшествует потенциальной способности. Возможному, по Аристотелю, предшествует некоторый принцип действительности, который действует независимо от принципа возможности [Там же. С. 244-245]. Напротив, у Н. Кузанского возможность быть тем и этим предполагает сначала саму по себе возможность. Согласно Н. Кузанскому, не может быть другого субстанциального или сущностного начала формального или материального, кроме самой по себе возможности [20. С. 425]. Возможность при этом определяется как нереализованное состояние вещей и явлений, или непроявленная тенденция бытия сущего, то, что может случиться, произойти. Ее можно трактовать также как условие или предпосылку какого-либо явления. По отношению к человеку возможное 
предстает как его бытие, находящееся в модусе становления, разворачивания [21. С. 21, 23].

В творчестве М.Н. Эпштейна возможному придается статус свойства потенциальных миров, происходящих в том числе из самого сущего, актуального, того, чем обладает наблюдатель, явлений совместимого с нами мира [22. С. 31$32,232]$. Возможное приобретает свойства имманентной метафизики, не метафизики потустороннего, а метафизики посюстороннего, находящегося рядом [Там же. С. 177]. Открытие новых возможностей, по Эпштейну, - это путь потенциации. Потенцировать, или «овозможивать», предмет, согласно философии возможного М.Н. Эпштейна, значит раскрыть возможности, которые предшествовали действительному бытию и / или из него вытекают [Там же. С. 231].

В этом отношении любая ориентация как способ самоопределения человека, отмечает В. Штегмайер, всегда происходит внутри жизни, для которой ориентирование - ее суть [23. С. 54-68]. Символический сценарий «заботы о себе» происходит в качестве продолжения базовых возможностей восприятия социальных явлений, жизненного мира или умвельта личности. Умвельт, отмечает Е.Н. Князева, - это мир смыслов живого существа. Он включает в себя мир его восприятия и мир действия, которые, соединяясь, образуют его внутренний мир (Innenwelt), определяют способ поведения в нем [24. С. 9798]. Ряд исследователей отождествляют умвельт человека с факторами общебиологического характера, к которым добавляются культурные особенности больших общностей, их категориальный строй языка [25. С. 201].

Жизнь, в частности в творчестве Дж. Батлер, понимается не только биологически, а, главным образом, в качестве части символической системы общества. Жить, по Дж. Батлер, значит осуществлять способность действовать определенным образом. Жизнь никогда не лишена политического смысла. Живое тело, замечает Дж. Батлер, не просто пассивно встроено в политикоправовую матрицу, но, вынужденно участвуя в ее активном исполнении, оказывается ее агентом [12. С. 218-219]. Возможное в качестве сценария коммуникации предстает символической сферой, инициирующей и преобразующей смыслы и формы «практик себя». При этом сценарии коммуникации как условия «заботы о себе», таким образом, представляют и различают возможные в культуре социума способы селекции, выборки «чужого» и «непонятного», воспроизводят определенные культурно-исторические значения социальной жизни человека в широком плане.

В этом отношении сценарии коммуникации представляют культурносимволические или «собственные значения» общества, конституирующие динамическое единство его элементов. Под «собственными значениями» исследователи понимают своеобразные социальные инварианты порядка, которые не могут быть сведены ни к консенсусу, ни к общим ценностям, ни к рациональности, обеспечивают не зависимую от консенсуса интеграцию, возвращение к ней, ее определенным смыслам [26. С. 105, 110]. В этом плане «забота о себе» в контексте культурно-символических сценариев коммуникации выражает стремление к сохранению и воспроизводству «собственных значений» общества как культурно-исторической целостности и сопряжена с проявлением его conatus или «воли к жизни», которая у Б. Спинозы представляет воображаемую причину бытия и его стремления к сохранению [27. C. $137,140-141]$. 
В результате социокультурные сценарии «заботы о себе» осуществляют самореференцию общества, которая в теории коммуникации Н. Лумана обеспечивает и объясняет закрытость социума, его неподконтрольность никакой внешней инстанции [28. С. 65]. Таким образом, сценарии выполняют функции воспроизводства социума и сохранения его отличности, автономности в окружающем мире, обеспечивают замкнутость «заботы о себе» на тех или иных значениях. При этом замкнутость, согласно Н. Луману, выступает условием познания, условием восприимчивости к окружающему миру [29. C. 108]. В этом плане сценарии коммуникации обеспечивают распознание познавательных возможностей личности в культуре, образующих взаимообусловленность и автономность коммуникаций социума.

При этом данные культурные сценарии воплощают некоторые знания о обществе, позволяющие личности отделять, различать «свое» от «чужого» в процессе «заботы о себе». Знание, согласно Н. Луману, есть некоторая структура, которая делает возможным аутопойезис коммуникации. В самом общем смысле знание задает правила, по которым ограничивается произвольность подсоединения коммуникации одной к другой [15. С. 69]. Знание, таким образом, возникают как определенные социальные ожидания. Сценарии, представляя когнитивные социальные ожидания, выражают готовность общества к изменениям, коррекции своих структур с целью внутренней адаптации социума к окружающему миру, в условиях влияния «чужого» и «непонятного», актуализации потребностей общества в обновлении символических средств самореференции общества. Данные ожидания представляют стремление общества к коррекции, готовность к научению, возникновению новых знаний как структур обеспечения аутопойезиса коммуникаций [Там же. С. 73]. В этом плане сценарии «заботы о себе» можно рассматривать в качестве символических форм социальных ожиданий, которые определяют готовность к научению и коррекции набора знаний, обеспечивающего аутопойезис коммуникаций социума, их целостность и автономию. Данный набор можно рассматривать как выражение самосознания общества или множественного социального cogito, реализующего разнообразное присоединение и отбор смыслов и норм социальных коммуникаций. Социальное cogito осуществляет самореференцию общества, формирует по своему подобию его коммуникации, преобразует влияния иных жизненных миров в «свои».

Как считает К.С. Пигров, общественное самосознание выражает образ активной направленности субъекта вовне и одновременно предполагает активную центростремительную силу, «втягивающую вовнутрь». Она, отмечает исследователь, направлена на «вбирание» предмета в себя в процессе превращения его в «свой» или поддержания его как «своего», вовлечения в себя, выражая в широком смысле жажду воли к власти [30. С. 16].

В этом плане культурные сценарии коммуникации, представляющие символический способ данного «вбирания» как «воли к власти», определяют возможности наличия и потенциал преодоления границ отличий смыслов и ценностей и одновременно обеспечения автономии человеческого социума. Культурные сценарии коммуникации нацелены на расширение границ общепринятых способов самореференции общества, составляют условия восприимчивости «заботы о себе» к эволюции культуры общества. Сценарий коммуникации, образуя возможность аутопойезиса коммуникации в социуме как 
предпосылки его автономии и жизнетворчества, являются возможностью бытия и самоизменения «заботы о себе». Как выражение самосознания общества, которое различает и обозначает специфику размыкания границ «заботы о себе», культурные сценарии коммуникации представляют горизонт ее множественных потенциальных приоритетов, ценностей. Разнообразие, дифференциации социального cogito, проявляющегося в многообразных сценариях коммуникации, создают условия для упорядочивания общества с разных позиций его наблюдения, с точки зрения многих свойств естественных установок личностей, их сообществ и способов социальной жизни как средств конструирования ее общезначимых проекций. Это дает возможность воссоздания, обновления интенций «заботы о себе», конституирует ее сопряженность с многообразием векторов эволюции культуры общества.

В результате культурные сценарии коммуникации, определяющие множественные смыслы и технологии социальной «заботы о себе», выступают в качестве структур самосознания общества или социального cogito, обеспечивающего аутопойезис коммуникации в социуме, выбор новых, других коммуникаций, «чужих» форм и смыслов общения. Вместе с тем сценарии представляют готовность к научению, возможности изменения самосознания общества или социального cogito, его культурно-символического инструментария, обеспечивающего аутопойезис социальной коммуникации и взаимосвязи понимания политических явлений. К данным возможностям можно отнести символические комплексы русской культуры, сопряженные с поиском истинного христианства, с со-участностью человеческого рода процессам преображения земли в Царство Христово, с культурно-историческими конструкциями и ценностными ориентациями мессианского проекта русской государственности, с ее значениями как проводника между «Земным и Небесным», с развитием возможностей нравственного и духовного совершенствования земной цивилизации как основы дальнейшей эволюции космоса и др. Данные значения формируют способы воспроизводства и конструирования личностью политических явлений, политической культуры, где сценарии «заботы о себе» выступают возможностью их «обучения» у расширяющегося многообразия культуры общества.

В целом политическую социализацию можно рассматривать как производную процессов «заботы о себе», представляющую практики самопреображения, самоконтроля и самопреобразования общества, позволяющую ему «управлять собой». «Забота о себе» предстает как значение политического. Его роль сопряжена с воспроизводством и трансформацией общественных форм саморегулирования, осознания границ и потенций, сохранения и раскрытия для человека, преобразования и расширения горизонтов его жизненного мира под влиянием чужого, непонятного, иных жизнемировых значений социального, представляет особенную способность постижения человеком истинного, связывающего континуум его отношений и многообразия естественных установок в обществе. При этом «забота о себе» сопряжена с понятием «conatus» как символически конструируемым стремлением к бытию или «воли к жизни» социума и личности, совокупностей их жизненных миров. Вместе с тем «забота о себе» выступает продуктом множества перформативных актов, конструирующих социум, связанных разными аспектами понимания и проектирования социальной ситуации человека, его позиции наблюде- 
ния в обществе. Перформативность инициирует возникновение новых аспектов «заботы о себе», возможностей новых смыслов и форм практик самопреобразования, самоконтроля и самопознания со стороны общества, делает «заботу о себе» предпосылкой и основой активных социокультурных сред, которые становятся посредниками в понимании политических явлений. Перформативность наделяет «заботу о себе» возможностью социокультурного конструирования политических феноменов, явлений политической культуры в процессе политической социализации человека.

«Забота о себе» происходит и трансформируется в контексте культурносимволических сценариев коммуникации, конструирующей действия и их разнообразие. Данные сценарии представляют общественные ожидания или структуры, необходимые для присоединения одной коммуникации к другой, понимания динамики политических феноменов. При этом сценарии конструируют «заботу о себе», вовлекают в нее личности и общества, образуют представление человека о возможных смыслах и символических формах самопреобразования и самоконтроля, происходящих в культуре общества. Сценарии коммуникации, включая в себя идею государства как эйдоса собирающего типа, позволяют организовывать «практики себя» в качестве множеств взаимообусловленных парадигм, действий и форм, ценностей и смыслов трансформации социума и личности, позволяют связывать различные практики и ценности «заботы о себе» во взаимосвязанный многообразный процесс самопознания и самопреобразования общества.

Символические сценарии коммуникации обусловлены «собственными значениями» социума или инвариантами порядка, которые создают независимую от консенсуса социальную интеграцию, обеспечивая самореференцию общества. В этом плане символические сценарии коммуникации создают замкнутость общественной «заботы о себе» на определенных культурноисторических значениях социальной эволюции, обеспечивают отличность, смыслы и формы автономии и самоизменений социума в окружающем мире. Данная замкнутость и ее культурные сценарии выступают условием восприимчивости «заботы о себе» к многообразию эволюции культуры общества.

Вместе с тем сценарии коммуникации представляют особые социокультурные ожидания как ее структуры. Данные ожидания выражают готовность к изменениям, коррекции компонентов самосознания общества с целью его адаптации к окружающему миру, в ситуации влияния «чужого» и «непонятного», представляя стремление общественного самосознания к научению. Поэтому культурные сценарии коммуникации выступают условием изменения способов самореференции общества, восприятия «заботой о себе» эволюции культуры социума. В этом плане сценарии «заботы о себе» можно рассматривать в качестве символических форм самосознания или множественного социального cogito. Оно обеспечивает аутопойезис коммуникации в социуме, символические правила, по которым коммуникация соединяется с другой, происходит выбор форм и смыслов общения, их символическое соединение. При этом социокультурные сценарии «заботы о себе» представляют стремление множественного социального cogito к своему воспроизводству и трансформации, к научению, новых знаниям как средствам реализации аутопойезиса коммуникации в социуме. Сценарии социальной «заботы о себе» выступают особыми возможностями существования и самокоррекции 
социального cogito, его символического инструментария, обеспечивающего аутопойезис коммуникации, взаимосвязь, воссоздание и деконструкции понимания политических явлений.

\section{Литература}

1. Лаврухин А. Политическое измерение философии Э. Гуссерля в свете критики Ф. Феллманна, Х. Аренд и Ю. Хабермаса // HORIZON. 2018. № 7 (2). С. 365-390.

2. Резник Ю.М. Новая гражданская общественность России как социально-этический проект межчеловечности // Вестник Российского философского общества. 2019. № 1-2. С. 20-31.

3. Рикер П. История и истина. СПб. : Алетейя, 2002. 400 с.

4. Фуко М. Герменевтика субъекта: Курс лекций, прочитанных в Коллеж-де-Франс в 19811982 учебном году. СПб. : Наука, 2007. 677 с.

5. Вирно П. Грамматика множества. К анализу форм современной жизни. М. : Канон+, 2013. $170 \mathrm{c}$.

6. Агамбен Дж. Оставшееся время: Комментарий к Посланию к Римлянам. М. : Новое лит. обозрение, 2018. $224 \mathrm{c}$.

7. Эпштейн М.Н. От знания - к творчеству. Как гуманитарные науки могут изменять мир. М. ; СПб. : Центр гуманитарных инициатив, 2016. 480 с.

8. Фишер-Лихте Э. Эстетика перформативности. М. : Канон+, 2015. 376 с.

9. Шмелева Е.В. Городское «множество» и эстетика перформативности: новые формы публичной культуры // Философский журнал. 2016. № 2. С. 114-125.

10. Кореикая М.А. Проблема власти в логике перформативного поворота // Контекст и рефлексия: философия о мире и человеке. 2018. Т. 7, № 6А. С. 76-86.

11. Остин Дж.Л. Три способа пролить чернила. Философские работы. СПб. : Алетейя, 2006. $335 \mathrm{c}$.

12. Симакова М. Альянсы хрупких тел, или Политика уязвимых жизней. Рецензия на книгу: Батлер Дж. (2017). Заметки к перформативной теории собрания // Социология власти. 2018. № 1. C. 215-226.

13. Фарафонова Д. Джорджо Агамбен. Язык философии и философия языка // Агамбен Дж. Царство и Слава. К теологической генеалогии экономики и управления. М.; СПб. : Изд-во Института Гайдара; Факультет свободных искусств и наук СПбГУ, 2019. С. 482-506.

14. Луман Н. Введение в системную теорию. М. : Логос, 2007. 360 с.

15. Луман Н. Истина, знание, наука как система. М. : Логос, 2016. 408 с.

16. Алиференко А.Ф. Современные проблемы науки о языке. М. : Флинта, 2006.416 с.

17. Кассирер Э. Избранное: опыт о человеке. М. : Гардарики, 1998. 779 с.

18. Лурье C.B. Культура и ее сценарий: имплицитный обобщенный сценарий как внутрикультурный интегратор // Общественные науки и современность. 2017. № 2. С. 160-161.

19. Аристотель. Метафизика. Соч.: в 4 т. М. : Мысль, 1975. Т. 1.550 с.

20. Кузанский Н. Сочинения: в 2 т. М. : Мысль, 1980. Т. 2. 471 с.

21. Резник Ю.М. Человек в мире возможностей: проектный подход (вместо введения) // Вопросы социальной теории. 2016. T. VIII, вып. 1-2: Человек в мире возможностей: образы будущего. С. 9-24.

22. Эпитейн М.Н. Философия возможного. СПб. : Алетейя, 2001. 232 с.

23. Штегмайер B. Жизнь как граница мышления // Стратегии ориентации в постсовременности. СПб. : Борей, 1996. С. 54-68.

24. Князева Е.Н. Биосемиотика: истоки междисциплинарного направления // Вопросы философии. 2018. № 11. С. 86-99.

25. Михайлов И.Ф. К онтологии жизненного мира человека: современный взгляд // Вопросы социальной теории. 2017. Т. ІХ. С. 200-211.

26. Антоновский А.Ю. Никлас Луман: Эпистемологические основания социологического конструктивизма // Луман Н. Общество как социальная система. М. : Логос, 2004. С. 104-116.

27. Майданский М.Д. Объективная телеология Спинозы // Историко-философский ежегодник. М. : Наука, 2003. С. 146-158.

28. Луман Н. Социальные системы : очерк общей теории. СПб. : Наука, 2007. 641 с.

29. Луман Н. Общество как социальная система. М. : Логос, 2004. 231 с.

30. Пигров К.С. Размышления о структуре национального самосознания // Вестник СанктПетербургского государственного университета. 2015. Сер. 17: Философия и конфликтология. Вып. 1. С. 12-21. 
Ivan V. Kirdjashkin, National research Tomsk State University (Tomsk, Russian Federation). E-mail:kirdjhkin@mail.ru

Vestnik Tomskogo gosudarstvennogo universiteta. Kul'turologiya i iskusstvovedeniye - Tomsk State University Journal of Cultural Studies and Art History, 2020, 39, pp. 33-44.

DOI: $10.17223 / 2220836 / 39 / 4$

POLITIKAL SOCIALISATION AS "CARE OF" IN CONTEXT OF CULTURALSYMBOLICAL SCENARIOS OF COMMUNICATIONS

Keywords: political socialization; "care of"; cultural-symbolical designing political; social consciousness.

In article political socialisation is considered as a part of processes personal and social "cares of", representing cultural experts of self-transformation, self-checking and society self-transformation. The given experts in work are presented as the general orientation of the political phenomena, allowing to form and transform the political culture of the person including a set of means of understanding of a society as interconnected the cultural-historical integrity informed on the basis of symbolical means of self-transformation of set the general outlook of individuals. In this plan "the care of" appears as area of existence and genesis of values political which role is interfaced to reproduction and transformation of forms social "managements of self", about a live continuum of the purposes and means of human relations. At the same time social "the care of" appears as a product performative the certificates designing a society under the influence of the changing social situation of the person. Performativnyj character social "cares of" creates possibilities socioculture designing of the political phenomena, political culture in the course of political socialisation of the person.

Thus social "the care of" occurs in a context of cultural-symbolical scenarios of communications which are caused by "own values" or rather mobile the unchangeable structures of a social order. In this respect symbolical scenarios of communications create isolation public "cares of" on certain historical values of society, form it difference, senses and forms of an autonomy and self-changes in world around. Scenarios "the care of" can be considered cares of as set of symbolical forms of public consciousness. It provides autopoecis communications in society, symbolical connection of communications, a choice of their means, institutional forms. Communications scenarios, expressing symbolical social "will to live", allow to organise "practice of" as sets the connected paradigms, actions and forms, values and senses of transformation of society and the person, the general purposeful processes of self-knowledge and society self-transformation.

In this respect the above-stated scenarios represent public expectations or the structures necessary for joining of one communications to another. Cultural scenarios of communications represent socioculture expectations concerning ways samoreference societies which express readiness for reproduction and changes, to self-correction of structures of consciousness of society, representing its aspiration to self-change, training, to perception of evolution of culture of a society. In this respect scenarios act as possibilities of existence and training ways autopoecisa the communications, entering into cultural toolkit of the social consciousness providing interrelation, a reconstruction and deconstructions of understanding of the political phenomena.

\section{References}

1. Lavrukhin, A. (2018) Political dimension of E. Husserl's phenomenology in the light of F. Fellmann's, H. Arendt's and J. Habermas' critique. HORIZON - Horizont. Studies in Phenomenology. 7(2). pp. 365-390. (In Russian). DOI: 10.21638/2226-5260-2018-7-2-365-390

2. Reznik, Yu.M. (2019) Novaya grazhdanskaya obshchestvennost' Rossii kak sotsial'noeticheskiy proekt mezhchelovechnosti [New civil society in Russia as a social and ethical project of interhumanity]. Vestnik Rossiyskogo filosofskogo obshchestva. 1-2. pp. 20-31.

3. Ricoeur, P. (2002) Istoriya i istina [History and Truth]. Translated from French. St. Petersburg: Aleteyya.

4. Foucault, M. (2007) Germenevtika sub"ekta: Kurs lektsiy, prochitannykh v Kollezh-de-Frans v 1981-1982 uchebnom godu [The Hermeneutics of the Subject: Lectures at the Collège de France 1981-1982]. Translated from French. St. Petersburg: Nauka.

5. Virno, P. (2013) Grammatika mnozhestva. K analizu form sovremennoy zhizni [A Grammar of the Multitude: For an Analysis of Contemporary Forms of Life]. Translated from Italian. Moscow: Kanon +.

6. Agamben, G. (2018) Ostavsheesya vremya: Kommentariy $k$ Poslaniyu $k$ Rimlyanam [The Time that Remains: A Commentary on the Letter to the Romans]. Translated from English. Moscow: Novoe lit. obozrenie.

7. Epstein, M.N. (2016) Ot znaniya - $k$ tvorchestvu. Kak gumanitarnye nauki mogut izmenyat' mir [From knowledge - to creativity. How the Humanities can change the world]. St. Petersburg: Tsentr gumanitarnykh initsiativ. 
8. Fischer-Lichte, E. (2015) Estetika performativnosti [Aesthetics of performativity]. Translated from German by N. Kandinskaya. Moscow: Kanon +.

9. Shmeleva, E.V. (2016) Urban 'multitude' and the aesthetics of performativity: new forms of public culture. Filosofskiy zhurnal - Philosophy Journal. 2. pp. 114-125. (In Russian). DOI: 10.21146/2072-0726-2016-9-2-114-126

10. Koretskaya, M.A. (2018) The problem of power in the logic of the performative turn. Kontekst i refleksiya: filosofiya o mire $i$ cheloveke - Context and Reflection: Philosophy of the World and Human Being. 7(6A). pp. 76-86. (In Russian).

11. Austin, J.L. (2006) Tri sposoba prolit' chernila. Filosofskie raboty [Three Ways of Spilling Ink]. Translated from English by V. Kiryushenko. St. Petersburg: Aleteyya.

12. Simakova, M. (2018) Alliances of Fragile Bodies, or Politics of Vulnerable Lifes. Review: Butler J. (2017) Zametki k performativnoi teorii sobraniya (Notes Toward a Performative Theory of Assembly). Sotsiologiya vlasti - Sociology of Power. 1. pp. 215-226. (In Russian).

13. Farafonova, D. (2019) Dzhordzho Agamben. Yazyk filosofii i filosofiya yazyka [Giorgio Agamben. The language of philosophy and philosophy of language]. In: Agamben, G. Tsarstvo $i$ Slava. K teologicheskoy genealogii ekonomiki i upravleniya [The Kingdom and the Glory: For a Theological Genealogy of Economy and Government]. Translated from English. Moscow; St. Petersburg: The Gaidar Institute. pp. 482-506.

14. Luhmann, N. (2007) Vvedenie $v$ sistemnuyu teoriyu [Introduction to the system theory]. Translated from German. Moscow: Logos.

15. Luhmann, N. (2016) Istina, znanie, nauka kak sistema [Truth, knowledge, science as a system]. Translated from German. Moscow: Logos.

16. Aliferenko, A.F. (2006) Sovremennye problemy nauki o yazyke [Modern problems of linguistics]. Moscow: Flinta.

17. Cassirer, E. (1998) Izbrannoe: opyt o cheloveke [Selected Works: An Essay on Man]. Translated from German. Moscow: Gardariki.

18. Lourie, S.V. (2017) The Culture and Its Script. Generalized Script as the Intracultural Integrator. Obshchestvennye nauki i sovremennost' - Social Sciences and Contemporary World. 2. pp. 160-161. (In Russian).

19. Aristotle. (1975) Metafizika [Metaphysics]. Vol. 1. Translated from Ancient Greek. Moscow: Mysl'.

20. Nicholas of Cusa (1980) Sochineniya: v 2 t. [Works. In 2 vols]. Moscow: Mysl'.

21. Reznik, Yu.M. (2016) Chelovek v mire vozmozhnostey: proektnyy podkhod (vmesto vvedeniya) [A person in the world of opportunities: a project approach (instead of introduction)]. In: Reznik, Yu.M. (ed.) Voprosy sotsial'noy teorii [Questions of Social Theory]. Vol. VIII (1-2). pp. 9-24.

22. Epstein, M.N. (2002) Filosofiya vozmozhnogo [Philosophy of the Possible]. St. Petersburg: Aleteyya.

23. Stegmaier, W. (1996) Zhizn' kak granitsa myshleniya [Life as a border of thinking]. In: Stegmaier, W., Frank, H. \& Markov, B.V. (eds) Strategii orientatsii v postsovremennosti [Orientation strategies in the post-modernity]. Translated from German by H. Frank. St. Petersburg: Borey. pp. 54-68.

24. Knyazev, E.N. (2018) Biosemiotics: The Origins of an Interdisciplinary Movement. Voprosy filosofii. 11. pp. 86-99. (In Russian).

25. Mikhaylov, I.F. (2017) K ontologii zhiznennogo mira cheloveka: sovremennyy vzglyad [Towards the ontology of the human life world: a modern view]. In: Reznik, Yu.M. (ed.) Voprosy sotsial'noy teorii [Questions of Social Theory]. 9. pp. 200-211.

26. Antonovsky, A.Yu. (2004) Niklas Luman: Epistemologicheskie osnovaniya sotsiologicheskogo konstruktivizma [Niklas Luhmann: Epistemological foundations of sociological constructivism]. In: Luhmann, N. Obshchestvo kak sotsial'naya sistema [The World Society as a Social System]. Translated from German. Moscow: Logos. pp. 104-116.

27. Maydansky, M.D. (2003) Ob"ektivnaya teleologiya Spinozy [Spinosa's objective teleology]. Istoriko-filosofskiy ezhegodnik. Moscow: Nauka. pp. 146-158.

28. Luhmann, N. (2007) Sotsial'nye sistemy: ocherk obshchey teorii [Social systems: an outline of the general theory]. Translated from German. St. Petersburg: Nauka.

29. Luhmann, N. (2004) Obshchestvo kak sotsial'naya sistema [The World Society as a Social System]. Translated from German. Moscow: Logos.

30. Pigrov, K.S. (2015) Reflections on the structure of national self-consciousness. Vestnik Sankt-Peterburgskogo gosudarstvennogo universiteta. 2015. Ser. 17. Filosofiya i konfliktologiya Vestnik of Saint-Petersburg University. Philosophy and Conflict Studies. 1. pp. 12-21. (In Russian). 